\title{
О СТЕПЕНИ УПОРЯДОЧЕНИЯ ПЛАГИОКЛАЗА В КРИСТАЛЛИЧЕСКИХ ПОРОДАХ СКВ. КОХИЛА НА ОСНОВЕ ДАННЫХ УГЛА ОПТИЧЕСКИХ ОСЕЙ $2 \mathrm{~V}$
}

Величина угла оптических осей $2 V$ полевых шпатов при определенном составе зависит главным образом от структурного состояния и в первую очередь - от степени упорядочения $\mathrm{Al}$ и $\mathrm{Si}$ (Марфунин, 1962). Поэтому структурное состояние плагиоклаза оценивается, помимо рентгеновских методов, еше и на основе значений $2 \mathrm{~V}$ (Галибин и др.. 1972).

В ходе детального изучения керна структурной скв. Кохила автором проведено массовое определение состава плагиоклаза. Общие результаты исследования (вариация состава, зависимость состава от материнской породы и т. д.) будут изложены в отдельной работе. Здесь рассмотрим только проблемы, возникшие при определении степени упорядоченности плагиоклаза на основе $2 \mathrm{~V}$.

Определению подвергались все важнейшие типы пород скв. Кохила: биотит-полевошпатовые и бнотит-амфиболовые гнейсы, амфиболиты и гранитоиды. Большинство определений принадлежит к метаморфитам. Из последних биотит-полевошпатовые и биотит-амфиболовые гнейсы часто сильно мигматизированы и имеют тонкополосчатое строение. Минеральные парагенезисы свидетельствуют о том, что толща кристаллических пород образовалась в условиях высокотемпературной субфации амфиболитовой фации метаморфизма.

Исследованный плагиоклаз имеет преимушественно андезиновый (№ 30-48) состав; только в трех случаях определен олигоклаз (№ 2527) и в одном случае - альбит (№ 5) (вторичный). Номер и $2 \mathrm{~V}$ плагиоклаза определены в 62 шлифах.

Состав плагиоклаза определялся методом четырехосного федоровского столика по двойникам, как исключение - по спайности. Использовалась диаграмма В. Никитина. Ошибка при повторных определениях не превышает $\pm 2-3 \%$ An. Для проверки метода и диаграммы три образца изучались иммерсионным методом. Проверка подтвердила правильность метода: составы плагиоклаза, полученные иммерсионным и федоровским методами, сходятся в пределах точности определения.

Угол оптических осей $2 \mathrm{~V}$ измерялся на федоровском столике ортоскопически по выходу двух осей; положение осей фиксировалось по меньшей мере трижды. Повторные определения показывают, что ошибка ниже $\pm 2^{\circ}$.

Параллельно с оптическим изучением три образца исследовались рентгенографически на дифрактометре УРС-50 ИМ. Был найден структурный фактор $2 \Theta(131)-2 \Theta(1 \overline{3} 1) \mathrm{CuK}_{\alpha}$, характеризующий степень рентгеновской упорядоченности плагиоклаза (Smith, Yoder, 1956).

Данные определений приведены в таблице и изображены на рис. 1 . 
Состав и $2 V$ плагиоклаза и $2 V$ калиевого полевого шпата в кристаллических породах скв. Кохила

\begin{tabular}{|c|c|c|c|c|}
\hline \multirow{2}{*}{$\begin{array}{l}\text { Номер } \\
\text { шлифа }\end{array}$} & \multirow{2}{*}{ Название породы } & \multicolumn{2}{|r|}{ Плагиоклаз } & \multirow{2}{*}{$\frac{\text { Калишпат }}{2 \mathrm{~V},}$} \\
\hline & & Номер & $2 V_{i}^{\circ}$ & \\
\hline 1 & 2 & 3 & 4 & 5 \\
\hline 237 & $\begin{array}{l}\text { Альбитизированный биотит-піо- } \\
\text { левошпатовый гнейс }\end{array}$ & 5 & +81 & $\begin{array}{l}-78,-78 \\
-80\end{array}$ \\
\hline $\begin{array}{l}273-1 \\
202\end{array}$ & $\begin{array}{l}\text { Катаклазнт } \\
\text { Бнотитовый гнейс из контакта } \\
\text { с гранитом }\end{array}$ & $\begin{array}{l}25 \\
27\end{array}$ & $\begin{array}{l}-83 \\
-84\end{array}$ & \\
\hline 259 & Биотит-полевошпатовый гнейс & 27 & +88 & $\begin{array}{l}-81,-82, \\
-83\end{array}$ \\
\hline K232 & Гранит & 29,31 & $-87,-82$ & $-68,-73$, \\
\hline $033-1$ & 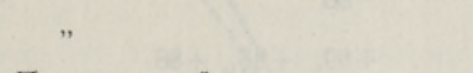 & 30 & $-79,-81,-82,-89$ & $\begin{array}{l}-79,-80 \\
-82\end{array}$ \\
\hline $\begin{array}{l}087 \\
102\end{array}$ & $\begin{array}{c}\text { Пегматоидный гранит } \\
,\end{array}$ & $\begin{array}{l}30 \\
30\end{array}$ & $\begin{array}{l}-86 \\
-79,-79,-84,-87\end{array}$ & $\begin{array}{l}-83 \\
-74,-74 \\
-74\end{array}$ \\
\hline & $\begin{array}{l}\text { Биотит-полевошпатовый гнейс } \\
\text { Пегматондный гранит }\end{array}$ & $\begin{array}{l}30 \\
30\end{array}$ & $\begin{array}{l}-87 \\
-85\end{array}$ & $\begin{array}{l}-76,-76, \\
-78\end{array}$ \\
\hline $\begin{array}{l}\text { K172 } \\
\text { K205 } \\
\text { K016 }\end{array}$ & $\begin{array}{l}\text { Гранит } \\
\text { Пегматоидный гранит } \\
\text { Бнотит-полевошпатовый гнейс }\end{array}$ & $\begin{array}{l}30 \\
30 \\
31\end{array}$ & $\begin{array}{l}-86 \\
-81 \\
-88,90,+89,+84\end{array}$ & $-82,-84$ \\
\hline 118 & Биотит-амфиболовый гнейс & 31 & $-80,-80,-84,-86$ & $\begin{array}{l}-60,-60, \\
-62\end{array}$ \\
\hline र148 & Бнотит-полевошпатовый гнейс & 31 & $-81,-85,-86,+89$ & $\begin{array}{l}-67,-67 \\
-72\end{array}$ \\
\hline K160 & Биотит-полевошпатовый гнейс & 31 & $-80,-85$ & $\begin{array}{l}-66,-68 \\
-68\end{array}$ \\
\hline & $\begin{array}{l}\text { Пегматоидный гранит } \\
\text { Бнотит-полевошпатовый гнейс }\end{array}$ & $\begin{array}{l}31 \\
32\end{array}$ & $\begin{array}{l}-88 \\
-87\end{array}$ & $\begin{array}{l}-74,-76 \\
-81\end{array}$ \\
\hline $\begin{array}{l}\text { K090 } \\
\text { K106 } \\
\text { K111 }\end{array}$ & 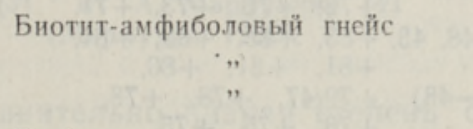 & $\begin{array}{l}32 \\
32 \\
32\end{array}$ & $\begin{array}{l}-84 \\
-79,-79,-84,-87 \\
-84\end{array}$ & $\begin{array}{l}-65,-68 \\
-64,-69 \\
-72\end{array}$ \\
\hline $\begin{array}{l}\mathrm{K} 340^{\mathrm{A}} \\
\mathrm{K} 351\end{array}$ & $\begin{array}{l}\text { Гнейсо-гранодиорит } \\
\text { Гранит }\end{array}$ & $\begin{array}{l}32 \\
32\end{array}$ & $\begin{array}{l}-84,-87 \\
-81,-82\end{array}$ & $\begin{array}{l}-66 \\
-69,-72, \\
-76\end{array}$ \\
\hline $\begin{array}{l}\text { Y064 } \\
\text { K121 }\end{array}$ & Био̆тит-полевошпатовый гнейс & $\begin{array}{l}33 \\
33\end{array}$ & $\begin{array}{l}-85 \\
-82,-85,-86 \\
-87,-88,+89,+85\end{array}$ & $-70,-72$ \\
\hline K125 & ", & $\begin{array}{l}33 \\
33\end{array}$ & $\begin{array}{l}-85,-87,-87,-88 \\
-85,-89\end{array}$ & $\begin{array}{l}-78,-80 \\
-76,-82 \\
-83\end{array}$ \\
\hline $\begin{array}{l}\text { K265 } \\
\text { K296 } \\
\text { K } 347\end{array}$ & $\begin{array}{l}\text { Пегматоидный гранит } \\
\text { Гранит } \\
\text { Гнейсо-гранодиорит }\end{array}$ & $\begin{array}{l}33 \\
33 \\
33\end{array}$ & $\begin{array}{l}-87 \\
-81 \\
-87\end{array}$ & $\begin{array}{l}-62,-63, \\
-66\end{array}$ \\
\hline $\begin{array}{l}\text { K039 } \\
\text { K045 }\end{array}$ & $\begin{array}{l}\text { Гранит } \\
\text { Биотит-лолевошпатовый гнейс }\end{array}$ & $\begin{array}{l}34 \\
34\end{array}$ & $\begin{array}{l}-86 \\
-86\end{array}$ & $\begin{array}{l}-74 \\
-83,-84 \\
-84\end{array}$ \\
\hline K107 & Биотит-амфиболовый гнейс & 34 & $\begin{array}{l}-79,-80-80,-84 \\
-88\end{array}$ & $\begin{array}{l}-64,-66, \\
-69\end{array}$ \\
\hline & & 34 & -85 & $\begin{array}{l}-58,-62 \\
-64,-68\end{array}$ \\
\hline $\begin{array}{l}\text { K228A } \\
\text { K323 } \\
\text { K336 } \\
\text { K345-1 }\end{array}$ & $\begin{array}{l}\text { Пироксеновый амфиболит } \\
\text { Биотит-полевошпатовый гнейс } \\
\text { Биотитовый гнейс из контакта }\end{array}$ & $\begin{array}{l}34 \\
34 \\
34 \\
34\end{array}$ & $\begin{array}{l}-88 \\
-86,-88,+89,+86 \\
-85 \\
-88\end{array}$ & $\begin{array}{ll}-82 \\
-64,-64\end{array}$ \\
\hline
\end{tabular}




\begin{tabular}{l|l|l|l|l}
\hline 1 & 2 & 3 & 4 & 5 \\
\hline
\end{tabular}

К350 Биотитовый амфиболит из кон- 33 такта с гранитом 34,34

К049 Биотит-полевошпатовый гнейс $35,34 \quad-85,-86$ $-83$

K150 35

$-83,-83$ $-70,-71$

K329

K011

K346

Биотит-амфиболовый гнейс

\section{5} Амфиболит

36

$-89$

$-83,-83,-86,-88-74$

K006

K035

Биотит-амфнболовый гнейс 37

Биотит-амфиболовый гнейс из 37 контакта с гранитом

K064 Биотитовый амфиболит из кон- 37 такта с гранитом

K067

K303

K311

Пироксеновый ӓффиболит

Пегматоидный гранит

K067А Бнотитовый амфиболит

K229

K084

K358

K031

K261

K359

K257

Биотит-амфиболитовый гнейс

Амфиболит

Биотит-амфиболитовый гнейс

Амфиболит

Биотитовый амфиболит

Амфиболит

37
37
37
38
$(36-39)$
38

$-81,-82,-83,-85$

$-85,-86,-86,-87$,

$\begin{array}{rrr}90 & -85,-86,-86,-87\end{array}$

$+83$

$39+86$

$40 \quad 90$

$41-88$

$42+86,+82$

$43,43+81,+81$

$41,43+85 / 41,+83,+80$

$44+79,+78,+78$,

K292

Пироксеновый амфиболит контакта с гранитом

К309 Пироксеновый амфиболит

K243

"

K358A

из 45,46

$+77 / 43,+77$

$+82$

$$
\begin{array}{ll}
46,47 & +84 \\
46(47) \quad & +83,+82,+81,+76, \\
& +76,+76,+73,+71, \\
47,48,48, & +83,+83,+82,+81, \\
50 & +81,+81,+80, \\
(47-48) & +79 / 47,+78,+78, \\
& +76,+75,+75, \\
& +73 / 50,+72,+71 / 48 \\
& +71,+71
\end{array}
$$

При мечания: 1. Набранные жирным шрифтом значения $2 V$ принадлежат различным индивидам одного двойника.

2. Из цифр, разделенных наклонной черточкой, первая обозначает величину $2 \mathrm{~V}$, вторая - состав плагиоклаза в том же зерне. тодом.

3. Номера плагиоклазов, приведенные в скобках, определялись иммерсионным ме-

На диаграмме состав $-2 V$ (рис. 1) плагиоклазы кристаллических пород скв. Кохила размещаются преимущественно в поле, ограничиваемом высокотемпературной кривой С. Шварцмана и низкотемпературной кривой А. Марфунина (1962). Точки распределяются почти по всему полю, образуя максимум на осевой линии поля или несколько выше, ближе к высокотемпературной кривой. Следовательно, на основе $2 V$ плагиоклазы скв. Кохила обладают главным образом промежуточной упорядоченностью, степень которой, оцененная по принципу Д. Слеммонса (Галибин и др., 1972), составляя в основном $30-80$, может варьировать в пределах $0-100$.

Степень рентrеновской упорядоченности в трех изученных образцах по диаграмме Д. Слеммонса (Галибин и др., 1972) составляет $75-85$. 
На других диаграммах (Дир и др., 1966; Smith, 1972) значения $2 \Theta(1 \overline{3} 1)-$ $2 \Theta(131)(1,72$ в обр. K067А $, 1,75$ в обр. K243, 1,75 в обр. К358А $)$ попадают на кривую низкотемпературного плагиоклаза со степенью упорядоченности $\sim 100$. Точную величину оптической упорядоченности в этих же образцах определить трудно, так как $2 V$ колеблется в очень широких пределах (таблица). Однако очевидно то, что степень оптического упорядочения ниже рентгеновского. Сходное отклонение наблюдается в данных

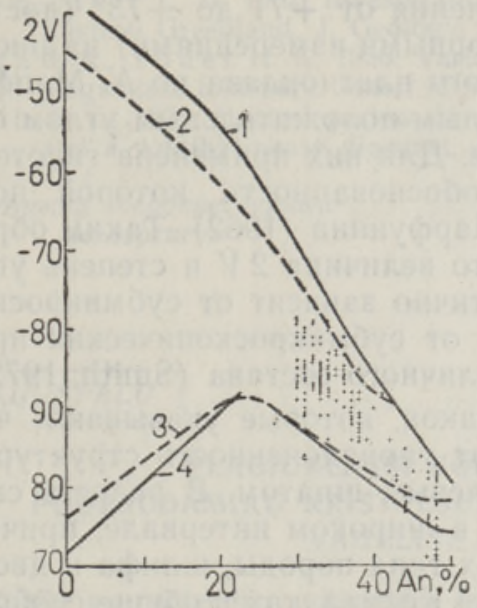

Рис. 1. Диаграмма состав $-2 \mathrm{~V}$ для плагиоклазов скв. Кохила. Кривые высокотемпературных плагиоклазов представлены по С. Шварцману (I) и Д. Р. Смиту (2), кривые низкотемпературных плагиоклазов - по Д. Р. Смиту (3) и А. Марфунину (4) (Марфунин, 1962).

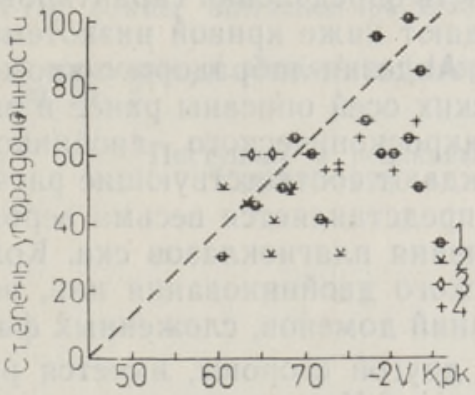

Рис. 2. Упорядоченность сосуществующих плагиоклаза и калиевого полевого шпата скв. Кохила: $I$ - биотит-полевошпатовые гнейсы, 2 - биотит-амфнболовые гнейсы, 3 - гнейсо-гранодиориты, 4 - граниты.

В. Галибина и др. (1972) и является, по-видимому, закономерным, отражая упорядочение на разных уровнях аналогично рентгеновской триклинности и $2 V$ в калиевых полевых шпатах.

Сравнительно низкая степень оптической упорядоченности плагиоклазов скв. Кохила оказалась несколько неожиданной. Хотя плагиоклаз метаморфических пород и слабо изучен, однако он считается хорошо упорядоченным (Марфунин, 1962; Дир и др., 1966). Так, по данным В. Галибина (1972), плагиоклазы амфиболитовой фации из докембрия Восточной Сибири отличаются высокой степенью упорядоченности.

Одной из причин такой неожиданности может быть суб́микроскопическое двойникование. В отличие от калишпатов присутствие последнего заметно влияет на величину $2 V$ плагиоклаза (Марфунин, 1962), а тем самым и на степень оптической упорядоченности. На возможность субмикроскопического двойникования плагиоклазов скв. Кохила, по мнению автора, указывает значительное колебание $2 \mathrm{~V}$ и, особенно, некоторые отклонения от нормы.

Изменчивость $2 \mathrm{~V}$ плагиоклазов скв. Кохила прослеживается как на уровне типов пород, так и в пределах отдельного шлифа и даже двойника (таблица). Если о различии $2 \mathrm{~V}$ соседних индивидов одного двойника имеется еще мало фактического материала (зарегистрировано в двух двойниках), то изменчивость в пределах шлифа бесспорно установлена. Из 18 более детально изученных шлифов, в которых $2 \mathrm{~V}$ определялся в трех и более зернах, колебания наблюдаются в 15 с интервалом 6-13을 что значительно превышает погрешность определения. Важно отметить 
при этом, что согласно многократным определениям состава плагиоклаза (таблица) последний остается практически постоянным. При исследовании вариаций $2 V$ велись наблюдения относительной величины зерна, гтепени идиоморфизма и характера микроскопического двойникования определяемых зерен плагиоклаза. Никакой заметной статистической связи между этими свойствами и значениями $2 \mathrm{~V}$ установить не удалось.

В шлифах К243 и К358А (амфиболиты) $2 \mathrm{~V}$ плагиоклаза варьирует от +83 до $+71^{\circ}$ при составе № $47-48$. Значения от +71 до +73 (достоверность определений гарантирована повторными измерениями) на рис. 1 попадают ниже крнвой низкотемпературного плагиоклаза по А. Марфунину. Андезин-лабрадоры с аномально малым положительным углом оптических осей описаны ранее в литературе. Для них применена гипотеза субмикроскопического двойникования, обоснованность которой подтверждают соответствующие расчеты А. Марфунина (1962). Таким образом, представляется весьма вероятным, что величина $2 \mathrm{~V}$ и степень упорядочения плагиоклазов скв. Кохила частично зависят от субмикроскопического двойникования или, возможно, от субмикроскопических прорастаний доменов, сложенных фазами различного состава (Smith, 1972).

С другой стороны, имеется ряд признаков, которые указывают, что значения $2 \mathrm{~V}$ в основном все же отражают упорядоченность структуры. Один из них - аналогия с калиевым полевым шпатом. В разрезе скв. Кохила $2 V$ калишпата колеблется также в широком интервале, причем изменчивость отмечается также на уровнях типа породы, шлифа и двойника. Қак фактические данные о калишпате Кохила, так и общие соображения (Марфунин, 1962) доказывают, что величина $2 \mathrm{~V}$ для калишпата служит мерой триклинного упорядочения. Во-вторых, степень упорядочения сосуществующих плагиоклаза и калишпата скв. Кохила в общем коррелятивна (рис. 2). Вместе с тем из диаграммы выявляется, что среди калишпатсодержащих пород наиболее низкой степенью упорядочения полевых шпатов характеризуются биотит-амфиболовые и, отчасти, биотит--полевошпатовые гнейсы. В-третьих, по предварительным данным, оптические (на основе $2 V$ ) упорядоченности плагиоклазов гранулитовой и амфиболитовой фаций Әстонии статистически отличаются: степень упорядочения первых в общем ниже степени упорядочения вторых. Такие же соотношения характерны для плагиоклазов докембрия Восточной Сибири (Галибин и др., 1972) и для калиевых полевых шпатов Эстонии.

Если $2 \mathrm{~V}$ плагиоклаза скв. Кохила в основном действительно зависит от упорядоченности структуры, то относительно низкую степень упорядочения можно объяснить следующими обстоятельствами. Во-первых, ряд минералогических признаков, в том числе спорадическое наличие антипертита, указывает на высокую степень метаморфизма, приближающуюся к условиям гранулитовой фации. Во-вторых, высказано предположение (Gay, Muir, 1962), что скорость упорядочения плагиоклазов зависит от состава, причем медленнее других упорядочивается плагиоклаз № 30-40. Низкая степень упорядочения плагиоклаза скв. Кохила обнаруживается именно в этом же интервале (рис. 1).

Дальнейшая углубленная геологическая интерпретация требует дополнительного детального и комплексного исследования. Особого внимания при этом заслуживает геологическое распространение изменчивости $2 V$ и физическая природа вариации. Материал скв. Кохила показывает, что оценка оптической упорядоченности на основе единичных определений $2 V$ не обоснована. 


\section{Л ИТЕ Р А Т У Р А}

Галиб ин В. А., Байкова В. С., Седов а И. С. 1972. Структурное состояние и состав полевых шпатов пород гранулитовой и амфиболитовой фаций (на примере центральной части Алданского щита и его обрамления). ДАН СССР, т. 205, № 3.

Д и р У. А., Х а у и Р. А., 3 у с м а н Дж. 1966. Породообразующие минералы. Т. 4. М.

М а р фунин А. С. 1962. Полевые шпаты - фазовые взаимоотношения, оптические свойства, геологическіое распределение. Тр. ИГЕМ, вып. 78.

G a y P., Muir L. D, 1962. Investigation of the feldspars of the Skaergaard intrusion, Eastern Greenland, J. Geology, 70, No. 5.

$\mathrm{Smith} \mathrm{J.} \mathrm{R.,} \mathrm{Yoder} \mathrm{H.} \mathrm{S.} \mathrm{1956.} \mathrm{Variations} \mathrm{in} \mathrm{X-ray} \mathrm{powder} \mathrm{diffraction} \mathrm{patterns} \mathrm{of}$ plagioclase feldspars. Amer. Miner., 41.

S m ith J. V., 1972. Critical review of synthesis and occurrence of plagioclase feldspars and a possible phase diagram. J. Geology, 80, No. 5.

Тартуский государственный университет
Поступила в редакцию

14/XII 1973

\section{T. KUUSPALU}

\section{PLAGIOKLASSI KORRASTUSASTMEST KOHILA \\ PUURSUDAMIKU KRISTALSETES KIVIMITES OPTILISTE TELGEDE VAHELISTE NURGA $2 \mathrm{~V}$ ALUSEL}

Kohila puursüdamiku amfiboliitse faatsiese kristalsete kivimite mineraloogilisel uurimisel määrati massiliselt plagioklassi $2 \mathrm{~V}$-d eesmärgiga hinnata plagioklassi korrastusastet D. Slemmonsi printsiibil. Tuvastati $2 \mathrm{~V}$ ulatuslik kõikumine nii sama koostisega kivimitüüpide lõikes kui ka üksiku ōhiku ja kaksiku piires, $2 \mathrm{~V}$ varieerumine peegeldab nähtavasti nii struktuurset seisundit kui ka submikroskoopilist kaksistumist. Optilise korrastusastme määramine $2 \mathrm{~V}$ üksikmäärangute alusel ei ole pōhjendatud.

\section{T. KUUSPALU}

\section{ON THE DEGREE OF ORDER OF PLAGIOCLASE IN THE CRYSTALLINE ROCKS OF KOHILA DRILL CORE ON THE BASIS OF OPTIC AXIAL ANGLES DATA}

A detailed study of the optic axial angle $2 \mathrm{~V}$ of plagioclase from amphibolite facies crystalline rocks of Kohila drill core (NW Estonia) has been carried out with the purpose of estimating the degree of order of plagioclase. The plagioclase $2 \mathrm{~V}$ shows considerable variations at a constant composition within the rock types, separate thin sections and also, probably, in separate individuals of the twins. The $2 \mathrm{~V}$ variations are believed to be the result of the structural state changes and of submicroscopical twinning. 